\title{
Risk factors for screw loosening in patients with adult degenerative scoliosis: the importance of paraspinal muscle degeneration
}

Wei Wang ${ }^{1,2}$, Weishi $\mathrm{Li}^{1,3^{*}}$ and Zhongqiang Chen ${ }^{1}$

\begin{abstract}
Background: Paraspinal muscle is an important component to maintain spinal stability. But the relationship between the degeneration of paraspinal muscle and postoperative screw loosening in patients with adult degenerative scoliosis has not been studied. The objective of this study was to investigate risk factors for screw loosening in patients with adult degenerative scoliosis, including paraspinal muscle degeneration.

Methods: We investigated 93 patients with adult degenerative scoliosis who underwent spinal interbody fusion and pedicle screw fixation surgery. The lateral curvature was located in the lumbar spine and the follow-up time was $\geq 2$ years. The patients were divided into loosening and non-loosening groups. Screw loosening was defined as a 1-mm or wider circumferential radiolucent line around the pedicle screw. We checked the cross-sectional area of paraspinal muscles, spinopelvic parameters, bone mineral density, number of fusion segment, and other factors. The potential risk factors for screw loosening were investigated by using binary logistical regression analysis.

Results: Fifty-seven patients showed screw loosening, which is 63.4\% of total. Compared with patients in the nonloosening group, the cross-sectional area of erector spinae and psoas major muscle at L5 level were significantly smaller in patients with screw loosening $(P<0.05)$. Among these factors, the number of fused segments and relative erector spinae total cross-sectional area were independent risk factors for screw loosening.

Conclusions: The degeneration of paraspinal muscle and the increase of fusion segment were independent factors for screw loosening in patients with adult degenerative scoliosis.
\end{abstract}

Keywords: Adult degenerative scoliosis, Risk factors, Screw loosening, Paraspinal muscle

\section{Background}

Adult degenerative scoliosis is a common adult spinal deformity, and the prevalence ranged from 30 to $68 \%$ in elderly [1-4].These patients often suffer from low back pain, lower limb radiation pain, impaired nerve function,

\footnotetext{
*Correspondence: puh3liweishi@163.com

1 Department of Orthopaedics, Peking University Third Hospital, No. 49 North Garden Road, Haidian District, Beijing 100191, China

${ }^{3}$ Beijing Key Laboratory of Spinal Disease Research, Beijing, China

Full list of author information is available at the end of the article
}

claudication, and so on [5, 6]. For patients without remission under conservative treatment, surgical treatment is required. Screw loosening is a common complication in patients after long-segment fusion and fixation surgery $[7,8]$, mainly occurring in proximal or distal vertebral bodies, which may be related to osteoporosis and stress concentration after fusion surgery.

Paraspinal muscle is an important component to maintain spinal stability, and the degeneration of paraspinal muscle is associated with a variety of diseases and

(c) The Author(s). 2021 Open Access This article is licensed under a Creative Commons Attribution 4.0 International License, which permits use, sharing, adaptation, distribution and reproduction in any medium or format, as long as you give appropriate credit to the original author(s) and the source, provide a link to the Creative Commons licence, and indicate if changes were made. The images or other third party material in this article are included in the article's Creative Commons licence, unless indicated otherwise in a credit line to the material. If material is not included in the article's Creative Commons licence and your intended use is not permitted by statutory regulation or exceeds the permitted use, you will need to obtain permission directly from the copyright holder. To view a copy of this licence, visit http://creativecommons.org/licenses/by/4.0/. The Creative Commons Public Domain Dedication waiver (http://creativecommons.org/publicdomain/zero/1.0/) applies to the data made available in this article, unless otherwise stated in a credit line to the data. 
patient's outcome [9-11]. In patients with adult spinal deformity, the atrophy of paraspinal muscle was associated with postoperative proximal junctional kyphosis (PJK) $[12,13]$, but there were few reports on the relationship between the degeneration of paravertebral muscle and screw loosening. A study found that paraspinal muscle degeneration was associated with screw loosening, and smaller cross-sectional area (CSA) and higher fat infiltration (FI) of paraspinal muscle were risk factors for sacral screw loosening [14]. But the study investigated a variety of diseases, including only four patients with adult scoliosis. To the best of our knowledge, the relationship between the degeneration of paraspinal muscle and postoperative screw loosening in patients with adult degenerative scoliosis has not been studied.

The purpose of this study was to investigate the relationship between paraspinal muscle degeneration and postoperative screw loosening and explore the risk factors for screw loosening in patients with adult degenerative scoliosis.

\section{Methods}

It was a single-center retrospective study which was approved by the Ethics Committee of Peking University Third Hospital, and the data of 93 patients with adult degenerative scoliosis who underwent surgical treatment in our hospital from 2010 to 2016 was analyzed. For this type of study, formal consent was not required.

Inclusion criteria were as follows: age $\geq 50$ years old, preoperative Cobb angle was $\geq 10^{\circ}$, lateral curvature located in the lumbar spine, the number of fused segments $\geq 3$, and the follow-up time was $\geq 2$ years. Exclusion criteria were as follows: scoliosis due to other causes, such as congenital scoliosis, idiopathic scoliosis, tuberculosis, and tumors; with a history of spinal surgery; with a lack of complete preoperative and postoperative follow-up data; with application of ilium screw; and so on. All patients underwent posterior median approach without special muscle preservation techniques [1]. The implanted pedicle screws were all conventional screws.

Screw loosening was evaluated by spinal X-ray (Discovery XR650 machine, General Electric Company) and spinal CT (Revolution CT, General Electric Company). As shown in Fig. 1, a halo sign showing a circumferential radiolucent line of $\geq 1 \mathrm{~mm}$ around the pedicle screw can be identified as screw loosening $[15,16]$.

Measurements of paraspinal muscles, including multifidus muscle (MF), erector spinae muscle (ES), and psoas major muscle (PS), were obtained from T2-weighted images. The Signa HDxt 3.0 T machine (General Electric Company) was used for all MRIs, with TR 2500 4000 ms, TE 50 120 ms. The slice thickness was $4 \mathrm{~mm}$ with a 4$\mathrm{mm}$ gap between each slice. During the examination, the patient was in the supine position with both lower limbs extended and the spine in neutral position. The plane parallel to the endplate under the corresponding vertebral body (L3-5) was selected for image measurement level.

The paraspinal muscle parameters including vertebral cross-sectional area, muscle total cross-sectional area, and muscle functional cross-sectional area were measured by the Image J software (Fig. 2). The regions of interest (ROI) were outlined around target muscles on the inferior endplate of vertebral body $[13,17]$. In order to eliminate the individual differences, the ratio of total muscle cross-sectional area to vertebral cross-sectional area was used as relative total muscle cross-sectional area (rtCSA), the ratio of functional muscle crosssectional area to vertebral cross-sectional area was used as relative muscle functional cross-sectional area (rfCSA), and the ratio of functional cross-sectional area
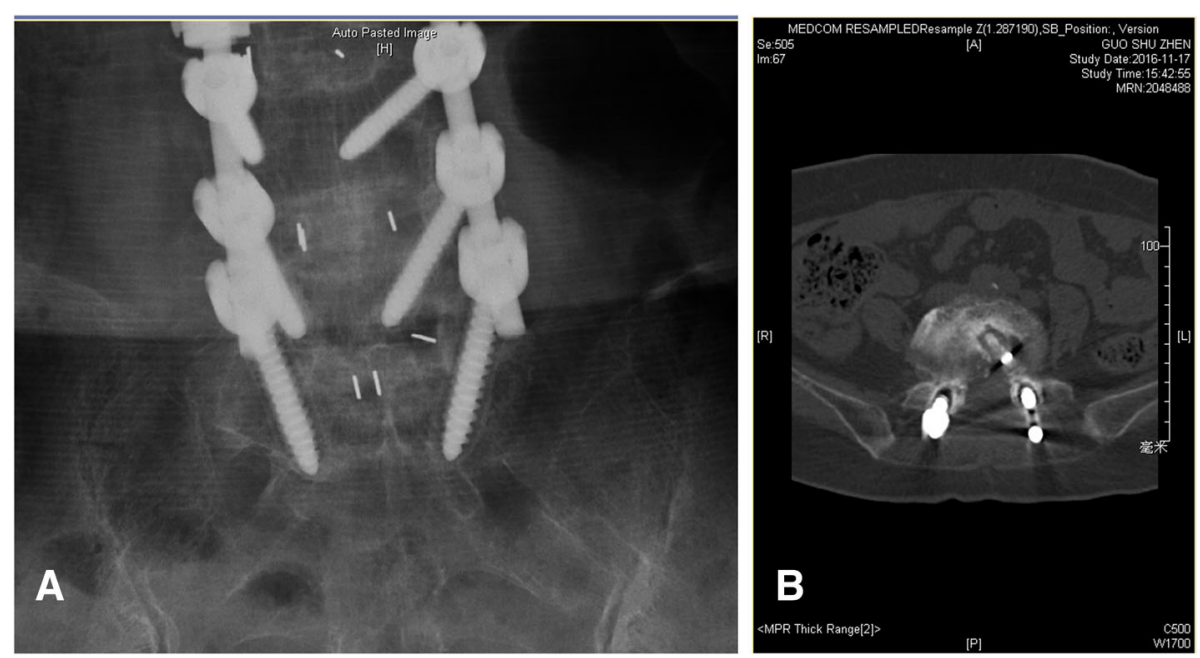

Fig. 1 Halo sign around screws on X-ray (A) and CT (B) 


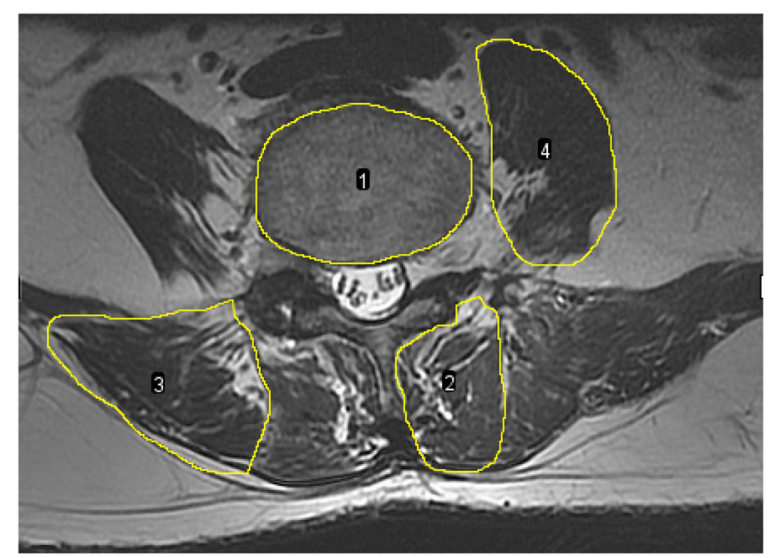

Fig. 2 Measurements of paraspinal muscles. (1) Vertebral cross-sectional area; (2) multifidus muscle cross-sectional area; (3) erector spinae muscle cross-sectional area; and (4) psoas muscle cross-sectional area

to the total cross-sectional area $(\mathrm{f} / \mathrm{t})$ was used to reflect fatty infiltration (FI). The functional cross-sectional area of the muscle was measured using threshold techniques $[17,18]$ (Fig. 3).

A Discovery XR650 machine (General Electric Company) was used for all images to measure spinopelvic sagittal parameters The radiographic parameters were measured by standing posteroanterior and lateral whole spine X-ray preoperatively. The parameters including sagittal vertical axis (SVA, the distance between the C7 plumb line and posterior superior corner on the top margin of S1),thoracic kyphosis (TK, the angle between the superior endplate of $\mathrm{T} 4$ and the inferior endplate of T12), lumbar lordosis (LL, the angle between the upper endplate of L1 and the sacral plate), pelvic incidence (PI, the angle between a perpendicular from the midpoint of upper endplate of S1 and a line connecting the center of

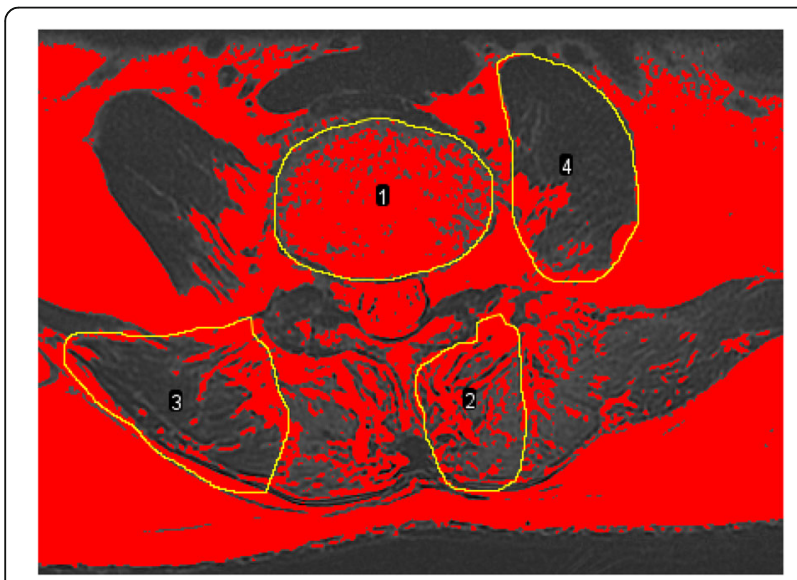

Fig. 3 Threshold technique was used to measure the functional cross-sectional area of muscles. Black area stands for the functional cross-sectional area the femoral head to the center of the upper endplate of $\mathrm{S} 1)$, pelvic tilt (PT, the angle between the vertical and the line through the midpoint of the sacral plate to femoral heads axis), and sacral slope (SS, the angle between the horizontal and the sacral plate) were measured by an experienced orthopedic surgeon.

SPSS version 23.0 (IBM company, USA) was used to analyze the collected data. All values were expressed as mean \pm standard deviation. For variables without a normal distribution, the Mann-Whitney $U$ test was used to analyze the difference between different groups, while the independent sample T-test was used to analyze variables with a normal distribution. The potential risk factors for screw loosening were investigated by using binary logistical regression analysis. Statistical significance was set at $\mathrm{p}$-value $<0.05$.

\section{Results}

\section{General data}

There were 93 patients in this study, including 21 males and 72 females. The average age of patients was $63.5 \pm$ 5.8 years with a range from 53 to 78 years. The mean follow-up time was $38.4 \pm 16.0$ (24-48) months. The mean value of body mass index (BMI) was $25.8 \pm 4.2 \mathrm{~kg} /$ $\mathrm{m}^{2}$. The mean blood loss was $1156.6 \pm 659.4 \mathrm{ml}$ and the mean operation time was $270.4 \pm 61.9 \mathrm{~min}$. The average number of fused segments was $5.5 \pm 1.3$, including 2 patients with 3 fused segments, 22 patients with 4 fused segments, 28 patients with 5 fused segments, 21 patients with 6 fused segments, 13 patients with 7 fused segments, 4 patients with 8 fused segments, and 3 patients with 9 fused segments. For the distribution of proximal fixed level, 14 patients were at T8-10, 65 patients were at T11-L1, and 14 patients were at L2. For the distribution of distal fixed level, 56 patients were with sacrum fixation and 37 patients were without sacrum fixation. The mean preoperative Cobb angle was $25.9 \pm 9.6^{\circ}$ and mean preoperative bone density was $-0.9 \pm 1.5$. For sagittal parameters, the mean SVA was $55.7 \pm 38.7 \mathrm{~mm}$, the mean PI was $48.1 \pm 10.5^{\circ}$, the mean PT was $23.6 \pm$ $10.3^{\circ}$, the mean SS was $24.5 \pm 9.6^{\circ}$, the mean LL was $25.5 \pm 15.8^{\circ}$, the mean TK was $21.0 \pm 12.3^{\circ}$, and the mean PI-LL was $22.6 \pm 16.0^{\circ}$ (Table 1 ).

\section{Paraspinal muscle parameters}

The measurements of paraspinal muscles, including multifidus muscle (MF), erector spinae muscle (ES), and psoas major muscle (PS), are shown in Table 2. At L3 level, the mean MrtCSA, ErtCSA, and PrtCSA were $80.3 \pm 22.5 \%, 229.8 \pm 58.8 \%$, and $95.7 \pm 28.8 \%$, respectively. The mean MrfCSA, ErfCSA, and PrfCSA were $41.0 \pm 18.4 \%, 140.6 \pm 51.1 \%$, and $87.1 \pm 28.1 \%$, respectively. The mean $\mathrm{Mf} / \mathrm{t}, \mathrm{Ef} / \mathrm{t}$, and $\mathrm{Pf} / \mathrm{t}$ were 49.5 $\pm 13.3 \%, 60.5 \pm 12.8 \%$, and $90.7 \pm 5.8 \%$, respectively. 
Table 1 Characteristic of patients

\begin{tabular}{|c|c|}
\hline Parameters & Value \\
\hline Age (year) & $63.5 \pm 5.8$ \\
\hline \multicolumn{2}{|l|}{ Gender } \\
\hline Male & 21 \\
\hline Female & 72 \\
\hline $\mathrm{BMI}\left(\mathrm{kg} / \mathrm{m}^{2}\right)$ & $25.8 \pm 4.2$ \\
\hline Lumbar T value & $-0.9 \pm 1.5$ \\
\hline Follow-up time (months) & $38.4 \pm 16.0$ \\
\hline Blood loss (ml) & $1156.6 \pm 659.4$ \\
\hline Operation time (min) & $270.4 \pm 61.9$ \\
\hline Hospital stay (days) & $12.6 \pm 6.9$ \\
\hline Number of fused segments & $5.5 \pm 1.3$ \\
\hline \multicolumn{2}{|l|}{ Proximal fixation segment (\%) } \\
\hline T8-10 & $14(15.1)$ \\
\hline T11-L1 & $65(69.9)$ \\
\hline L2 & $14(15.1)$ \\
\hline \multicolumn{2}{|l|}{ Distal fixation segment (\%) } \\
\hline Sacrum fixation & $56(60.2)$ \\
\hline Non-sacrum fixation & 37 (39.8) \\
\hline \multicolumn{2}{|l|}{ Screw loosening (\%) } \\
\hline Loosening & $59(63.4)$ \\
\hline Non-loosening & $34(36.6)$ \\
\hline Cobb angle $\left(^{\circ}\right)$ & $25.9 \pm 9.6$ \\
\hline \multicolumn{2}{|l|}{ Sagittal parameters } \\
\hline SVA (mm) & $55.7 \pm 38.7$ \\
\hline $\mathrm{PI}\left({ }^{\circ}\right)$ & $48.1 \pm 10.5$ \\
\hline PT $\left({ }^{\circ}\right)$ & $23.6 \pm 10.3$ \\
\hline SS $\left(^{\circ}\right)$ & $24.5 \pm 9.6$ \\
\hline $\mathrm{LL}\left({ }^{\circ}\right)$ & $25.5 \pm 15.8$ \\
\hline TK $\left(^{\circ}\right)$ & $21.0 \pm 12.3$ \\
\hline PI-LL $\left(^{\circ}\right)$ & $22.6 \pm 16.0$ \\
\hline
\end{tabular}

BMI body mass index, SVA sagittal vertical axis, $P$ I pelvic incidence, $P T$ pelvic tilt, SS sacral slope, LL lumbar lordosis, TK thoracic kyphosis, PI-LL PI minus LL

At L4 level, the mean MrtCSA, ErtCSA, and PrtCSA were $109.6 \pm 29.0 \%, 202.3 \pm 48.3 \%$, and $129.9 \pm$ $36.9 \%$, respectively. The mean MrfCSA, ErfCSA, and PrfCSA were $55.3 \pm 24.0 \%, 111.9 \pm 39.8 \%$, and 119.6 $\pm 35.0 \%$, respectively. The mean $\mathrm{Mf} / \mathrm{t}, \mathrm{Ef} / \mathrm{t}$, and $\mathrm{Pf} / \mathrm{t}$ were $49.6 \pm 14.0 \%, 54.8 \pm 11.9 \%$, and $92.1 \pm 6.2 \%$, respectively. At L5 level, the mean MrtCSA, ErtCSA, and PrtCSA were $135.3 \pm 36.3 \%, 142.4 \pm 53.4 \%$, and $135.6 \pm 38.2 \%$, respectively. The mean MrfCSA, ErfCSA, and PrfCSA were $62.3 \pm 28.1 \%, 63.0 \pm 30.9 \%$, and $133.4 \pm 76.2 \%$, respectively. The mean Mf/t, Ef/t, and $\mathrm{Pf} / \mathrm{t}$ were $45.5 \pm 14.2 \%, 43.7 \pm 11.9 \%$, and $97.8 \pm$ $42.2 \%$, respectively.
Table 2 Measurements of paraspinal muscles at different levels

\begin{tabular}{|c|c|}
\hline Parameters & Value \\
\hline \multicolumn{2}{|l|}{ L3 (\%) } \\
\hline MrtCSA & $80.3 \pm 22.5$ \\
\hline ErtCSA & $229.8 \pm 58.8$ \\
\hline PrtCSA & $95.7 \pm 28.8$ \\
\hline MrfCSA & $41.0 \pm 18.4$ \\
\hline ErfCSA & $140.6 \pm 51.1$ \\
\hline PrfCSA & $87.1 \pm 28.1$ \\
\hline $\mathrm{Mf} / \mathrm{t}$ & $49.5 \pm 13.3$ \\
\hline $\mathrm{Ef} / \mathrm{t}$ & $60.5 \pm 12.8$ \\
\hline $\mathrm{Pf} / \mathrm{t}$ & $90.7 \pm 5.8$ \\
\hline \multicolumn{2}{|l|}{ L4 (\%) } \\
\hline MrtCSA & $109.6 \pm 29.0$ \\
\hline ErtCSA & $202.3 \pm 48.3$ \\
\hline PrtCSA & $129.9 \pm 36.9$ \\
\hline $\operatorname{MrfCSA}$ & $55.3 \pm 24.0$ \\
\hline ErfCSA & $111.9 \pm 39.8$ \\
\hline PrfCSA & $119.6 \pm 35.0$ \\
\hline $\mathrm{Mf} / \mathrm{t}$ & $49.6 \pm 14.0$ \\
\hline $\mathrm{Ef} / \mathrm{t}$ & $54.8 \pm 11.9$ \\
\hline $\mathrm{Pf} / \mathrm{t}$ & $92.1 \pm 6.2$ \\
\hline \multicolumn{2}{|l|}{ L5 (\%) } \\
\hline MrtCSA & $135.3 \pm 36.3$ \\
\hline ErtCSA & $142.4 \pm 53.4$ \\
\hline PrtCSA & $135.6 \pm 38.2$ \\
\hline MrfCSA & $62.3 \pm 28.1$ \\
\hline ErfCSA & $63.0 \pm 30.9$ \\
\hline PrfCSA & $133.4 \pm 76.2$ \\
\hline $\mathrm{Mf} / \mathrm{t}$ & $45.5 \pm 14.2$ \\
\hline $\mathrm{Ef} / \mathrm{t}$ & $43.7 \pm 11.9$ \\
\hline $\mathrm{Pf} / \mathrm{t}$ & $97.8 \pm 42.2$ \\
\hline
\end{tabular}

$M$ multifidus muscle, $E$ erector spinae muscle, $P$ psoas major muscle, $r t C S A$ relative total cross-sectional area, rfCSA relative functional cross-sectional area, $f / t$ the ratio of the functional cross-sectional area and total cross-sectional area

\section{Comparison between the loosening group and non- loosening group}

All patients were divided into the loosening group and non-loosening group according to whether screw loosening occurred in the last follow-up. There were $59 \mathrm{pa}$ tients in loosening group and 34 patients in nonloosening group. The age of patients with screw loosening was $64.0 \pm 6.1$ years, while that in non-loosening group was $62.7 \pm 5.2$ years $(\mathrm{P}=0.276)$. The number of fused segments for patients with screw loosening was 5.7 \pm 1.4 , while that in non-loosening group was $5.2 \pm 1.2$ $(\mathrm{P}=0.075)$. Besides, the value of $\mathrm{BMI}$, ratio of gender, bone density, preoperative Cobb angle, and sagittal 
parameters did not have significant difference between the two groups (Table 3).

To investigate the correlation between paraspinal muscle degeneration and screw loosening, the measurements of paraspinal muscle were compared between two groups and the results are recorded in Table 4. Compared with patients in the non-loosening group, the ErtCSA, ErfCSA, and PrtCSA at L5 level of patients in the loosening group were significantly smaller $(\mathrm{P}<0.05)$. Therefore, in our study, the atrophy of paraspinal muscle was correlated with screw loosening.

To further explore the effect of paraspinal muscle degeneration on screw loosening, the binary logistic regression analysis was used. The independent variables included age, gender, BMI, number of fused segment, ErtCSA, lumbosacral fusion, and preoperative Cobb angle. As the result shown in Table 5, the number of fused segment and ErtCSA were independent factors for screw loosening. Compared with patients with short fused segments, patients with more than 5 fused segments had a 2.882-fold risk of screw loosening. The greater the ErtCSA was, the lower the rate of screw loosening was. Therefore, in our study, paraspinal muscle plays a protective role in screw loosening.

\section{Discussion}

Screw loosening is a common complication for patients with fusion and fixation surgery and it is influenced by many factors, such as bone density and operation segment $[14,19,20]$. As an important composition to maintain the stability of spine, the degeneration of paraspinal muscle is of great interest [21,22]. There was one study found that the degeneration of paraspinal muscle was correlated with S1 screw loosening [14]. But the relationship between the atrophy of paraspinal muscle and screw loosening was unclear in patients with adult degeneration scoliosis.

A 1-mm or wider circumferential radiolucent line around the pedicle screw can be identified as screw loosening $[15,16]$. The incidence of screw loosening ranged widely among those studies. Tokuhashi et al. found that the rate of screw loosening after single-segment fusion operation was $7.4 \%$, while the incidence was more than $40 \%$ in patients with three or more fused segments [23]. In our investigation, the incidence of screw loosening was $63.4 \%$, which was higher than previous studies. It may be related to the fact that the patients in this study were older and the fused segments were longer compared with previous study [23].

The gender, bone density, and sagittal parameters were not significantly different between the loosening group and non-loosening group. Compared with patients in the non-loosening group, patients in the loosening group were older and their number of fused segments was longer, but their difference was not statistically significant. Among these paraspinal muscle parameters, the CSA of

Table 3 Comparison between the loosening group and non-loosening group

\begin{tabular}{|c|c|c|c|}
\hline Parameters & Loosening & Non-loosening & $P$ value \\
\hline Gender (M/F) & $16 / 43$ & $5 / 29$ & 0.168 \\
\hline Age (year) & $64.0 \pm 6.1$ & $62.7 \pm 5.2$ & 0.276 \\
\hline BMI (kg/m2) & $25.5 \pm 4.2$ & $26.4 \pm 4.2$ & 0.354 \\
\hline Lumbar T value & $-0.8 \pm 1.5$ & $-1.1 \pm 1.6$ & 0.434 \\
\hline Cobb angle $\left(^{\circ}\right)$ & $27.2 \pm 9.2$ & $23.6 \pm 9.9$ & 0.078 \\
\hline Number of fused segments & $5.7 \pm 1.4$ & $5.2 \pm 1.2$ & 0.075 \\
\hline Operation time (min) & $277.4 \pm 66.6$ & $258.4 \pm 51.4$ & 0.154 \\
\hline Blood loss (ml) & $1142.5 \pm 551.8$ & $1180.9 \pm 822.2$ & 0.431 \\
\hline Hospital stay (day) & $13.1 \pm 8.1$ & $11.7 \pm 4.1$ & 0.782 \\
\hline Lumbosacral fixation (YES/NO) & $37 / 22$ & $19 / 15$ & 0.517 \\
\hline Proximal segments (T/TL/L) & $10 / 42 / 7$ & $4 / 23 / 7$ & 0.469 \\
\hline \multicolumn{4}{|l|}{ Sagittal parameters } \\
\hline SVA (mm) & $59.4 \pm 43.4$ & $49.3 \pm 28.5$ & 0.180 \\
\hline $\mathrm{PI}\left({ }^{\circ}\right)$ & $47.3 \pm 10.0$ & $49.6 \pm 11.3$ & 0.308 \\
\hline $\mathrm{PT}\left({ }^{\circ}\right)$ & $23.5 \pm 10.3$ & $23.9 \pm 10.5$ & 0.861 \\
\hline SS $\left(^{\circ}\right)$ & $23.8 \pm 8.9$ & $25.7 \pm 10.8$ & 0.351 \\
\hline LL $\left({ }^{\circ}\right)$ & $24.9 \pm 14.8$ & $26.7 \pm 17.4$ & 0.604 \\
\hline TK $\left(^{\circ}\right)$ & $21.6 \pm 13.1$ & $20.0 \pm 10.9$ & 0.535 \\
\hline PI-LL $\left(^{\circ}\right)$ & $22.4 \pm 16.4$ & $22.9 \pm 15.6$ & 0.876 \\
\hline
\end{tabular}

BMI body mass index, SVA sagittal vertical axis, PI pelvic incidence, PT pelvic tilt, SS sacral slope, LL lumbar lordosis, TK thoracic kyphosis, PI-LL PI minus LL 
Table 4 The difference of paraspinal muscle measurements between the two groups

\begin{tabular}{|c|c|c|c|}
\hline Measurements & Loosening & Non-loosening & $P$ value \\
\hline \multicolumn{4}{|l|}{ L3 (\%) } \\
\hline MrtCSA & $79.7 \pm 21.8$ & $81.5 \pm 24.0$ & 0.709 \\
\hline ErtCSA & $222.6 \pm 58.4$ & $242.2 \pm 58.1$ & 0.123 \\
\hline PrtCSA & $94.0 \pm 30.6$ & $98.8 \pm 25.6$ & 0.444 \\
\hline MrfCSA & $40.8 \pm 17.4$ & $41.2 \pm 20.4$ & 0.928 \\
\hline ErfCSA & $136.0 \pm 48.2$ & $148.4 \pm 55.8$ & 0.263 \\
\hline PrfCSA & $85.7 \pm 30.2$ & $89.6 \pm 24.1$ & 0.524 \\
\hline $\mathrm{Mf} / \mathrm{t}$ & $50.3 \pm 12.3$ & $48.1 \pm 14.8$ & 0.445 \\
\hline$E f / t$ & $60.4 \pm 12.2$ & $60.6 \pm 13.9$ & 0.943 \\
\hline $\mathrm{Pf} / \mathrm{t}$ & $90.7 \pm 6.3$ & $90.7 \pm 5.0$ & 0.974 \\
\hline \multicolumn{4}{|l|}{ L4 (\%) } \\
\hline MrtCSA & $108.7 \pm 29.4$ & $111.1 \pm 28.5$ & 0.706 \\
\hline ErtCSA & $199.4 \pm 50.4$ & $207.4 \pm 44.8$ & 0.443 \\
\hline PrtCSA & $129.0 \pm 36.6$ & $131.4 \pm 38.0$ & 0.756 \\
\hline MrfCSA & $54.5 \pm 24.1$ & $56.5 \pm 24.1$ & 0.700 \\
\hline ErfCSA & $110.1 \pm 40.3$ & $114.9 \pm 39.2$ & 0.581 \\
\hline PrfCSA & $118.5 \pm 35.8$ & $121.4 \pm 33.9$ & 0.698 \\
\hline $\mathrm{Mf} / \mathrm{t}$ & $49.6 \pm 14.8$ & $49.6 \pm 12.6$ & 1 \\
\hline $\mathrm{Ef} / \mathrm{t}$ & $54.8 \pm 11.7$ & $54.9 \pm 12.5$ & 0.963 \\
\hline $\mathrm{Pf} / \mathrm{t}$ & $91.7 \pm 6.9$ & $92.7 \pm 4.6$ & 0.738 \\
\hline \multicolumn{4}{|l|}{ L5 (\%) } \\
\hline MrtCSA & $131.1 \pm 37.2$ & $142.7 \pm 34.0$ & 0.140 \\
\hline ErtCSA & $130.1 \pm 47.4$ & $163.7 \pm 57.0$ & $0.003^{* *}$ \\
\hline PrtCSA & $129.3 \pm 34.7$ & $146.6 \pm 41.9$ & $0.034^{*}$ \\
\hline MrfCSA & $61.7 \pm 27.8$ & $63.5 \pm 29.1$ & 0.768 \\
\hline ErfCSA & $57.5 \pm 27.5$ & $72.6 \pm 34.5$ & $0.022^{*}$ \\
\hline PrfCSA & $132.1 \pm 91.9$ & $135.6 \pm 36.6$ & 0.130 \\
\hline $\mathrm{Mf} / \mathrm{t}$ & $46.6 \pm 14.2$ & $43.5 \pm 14.2$ & 0.322 \\
\hline$E f / t$ & $43.9 \pm 12.1$ & $43.5 \pm 11.6$ & 0.881 \\
\hline $\mathrm{Pf} / \mathrm{t}$ & $100.6 \pm 52.8$ & $92.9 \pm 4.9$ & 0.116 \\
\hline
\end{tabular}

$M$ multifidus muscle, $E$ erector spinae muscle, $P$ psoas major muscle, $r t C S A$ relative total cross-sectional area, rfCSA relative functional cross-sectional area, $\mathrm{f} / \mathrm{t}$ the ratio of the functional cross-sectional area and total cross-sectional area

Table 5 The risk factors for screw loosening

\begin{tabular}{llll}
\hline Parameters & Regression coefficient & P value & OR value \\
\hline Fused levels & 1.059 & 0.029 & $2.882(1.115-7.454)$ \\
ErtCSA & -1.142 & 0.013 & $0.319(0.130-0.782)$ \\
Consistent value & 1.792 & 0.016 & \\
\hline
\end{tabular}

E, erector spinae muscle; $r t C S A$, relative total cross-sectional area
ES at L5 level was significantly different between the two groups. The CSA of ES at L3 and L4 level was not statistically significant between the two groups. By binary logistical regression analysis, we found that the number of fused segments and degeneration of paraspinal muscle were independent risk factors for screw loosening.

The number of fused segments was a common risk factor for screw loosening. With increased fused segments, the incidence of screw loosening increased significantly $[14,23]$. Kim et al. found that the rate of S1 screw loosening was higher in patients with 3 or 4 fused segments than 1 fused segment [14]. In this study, all patients had 3 or more fused segments and the rate of screw loosening in patients with more than 5 fused segments was higher than that in patients with 3 to 5 fused segments by almost thrice. The possible explanation was that longer fused segments restricted the motion of spine and increased the stress on screw. So we suggest to consider the fused segment before surgery.

Degeneration of paraspinal muscle was also another risk factor for screw loosening. The cross-sectional area and fatty infiltration of paraspinal muscle were two key parameters to evaluate the atrophy of paraspinal muscle [10, 24-26]. Kim et al. found that screw loosening was related to the degeneration of paraspinal muscle in patients with lumbar degenerative diseases. Patients with screw loosening had smaller CSA of paraspinal muscle at L5-S1 level [14]. But their study only included four patients with degenerative scoliosis. In this investigation, we analyzed the data of patients with adult degenerative scoliosis and found that patients with screw loosening had smaller ErtCSA, ErfCSA, and PrtCSA than patients without screw loosening. By using binary logistic regression analysis, ErtCSA at L5 level was a protective factor for screw loosening.

Paraspinal muscle is important for the stability of spine. Erector spinae muscle and multifidus muscle are important part of extensor muscles to maintain lumbar stability [27-29], while psoas major muscle provides support for flexion of hip joint and lumbar stability [30]. The cross-sectional area of muscle was associated with the muscle strength [31]. Muscle strength decreased with the cross-sectional area decreased, which had a negative influence on the spinal stability and increased the stress of pedicle screw. It may be related to the fact that the rate of screw loosening was higher in patients with worse degeneration of paraspinal muscle.

Fatty infiltration is also another parameter in evaluating the quality of paraspinal muscles. The signal intensity was higher in patients with screw loosening than patients without screw loosening, which suggested that the fatty infiltration was worse [14]. But in this study, the fatty infiltration of paraspinal muscle did not have significant difference between two groups. It may be 
related to the different measurement techniques. In our study, we measured the fatty infiltration of paraspinal muscle by Image J software, while Kim et al. measured the signal intensity of muscle to reflect the amount of intramuscular fat content [14]. There is not a gold standard in measuring the fatty infiltration of paraspinal muscle, so it needs more efforts to explore this problem. Besides, fatty component in muscles could not provide contractile forces and the fatty infiltration of muscle did not associate with muscle strength [31].

Previous studies reported that the lower bone density and sacrum fusion were risk factors of screw loosening $[14,32]$. But in this study, the distribution of both distal and proximal fused level was not statistically significant between the two groups. Another investigation also found that the lumbosacral fusion was not associated with screw loosening [7]. The explanation for different results was that the other factors had a stronger impact than the influence of lumbosacral fixation on pedicle screws stability. Besides, the bone density was not significantly different between the two groups in this study. The decrease of bone density was associated with the increase of age [33]. Patients' age was not different between two groups, which may lead to the similar bone density.

There were some limitations in this study. Firstly, it was a single-center retrospective study which may bring a selection bias. Besides, the sample size of this research was small. A prospective study with large sample size will be needed to confirm our results. Although it had limitations, this study investigated the relationship between the degeneration of paraspinal muscle and screw loosening. Unlike other studies which only measured paraspinal muscle at one level, we measured the paraspinal muscle from L3 to L5 levels. We found that the decrease of cross-sectional area in erector spinae muscle was independently associated with screw loosening. It could provide help for further prospective investigation about the relation between paraspinal muscles and pedicle screw loosening, the risk factor of screw loosening and so on.

\section{Conclusions}

The cross-sectional area of erector spinae muscle was significantly smaller and the number of operated levels was longer in patients with screw loosening than that in patients without screw loosening. The degeneration of paraspinal muscle and the increase of operated levels were independent factors for screw loosening in patients with adult degenerative scoliosis.

\section{Abbreviations}

BMI: Body mass index; MF: Multifidus muscle; ES: Erector spinae muscles; tCSA: Total cross-sectional area; fCSA: Functional cross-sectional area; FI: Fatty infiltration; PS: Psoas major muscle

\section{Acknowledgements}

Not applicable

\section{Authors' contributions}

WW conceived the project and analyzed the data. All authors contributed towards the interpretation and the collection of the data. All authors wrote and approved the final manuscript.

\section{Funding}

Not applicable

Availability of data and materials

The data used and analyzed during the current study was available from the corresponding author on reasonable request.

\section{Declarations}

Ethics approval and consent to participate

All procedures performed in studies involving human participants were in accordance with the ethical standards of the institutional and/or national research committee and with the 1964 Helsinki declaration and its later amendments or comparable ethical standards. This study was approved by Peking University Third Hospital Ethics Committee.

Consent for publication

Not applicable.

\section{Competing interests}

The authors declare that they have no competing interests.

\section{Author details}

'Department of Orthopaedics, Peking University Third Hospital, No. 49 North Garden Road, Haidian District, Beijing 100191, China. ${ }^{2}$ Peking University Health Science Center, No. 38 Xueyuan Road, Haidian District, Beijing 100191, China. ${ }^{3}$ Beijing Key Laboratory of Spinal Disease Research, Beijing, China.

Received: 31 January 2021 Accepted: 28 June 2021

Published online: 12 July 2021

References

1. Silva FE, Lenke LG. Adult degenerative scoliosis: evaluation and management. Neurosurg Focus. 2010;28(3):E1. https://doi.org/10.3171/201 0.1.FOCUS09271.

2. Robin GC, Span Y, Steinberg R, Makin M, Menczel J. Scoliosis in the elderly: a follow-up study. Spine (Phila Pa 1976). 1982;7(4):355-9. https://doi.org/10.1 097/00007632-198207000-00005

3. Schwab F, Dubey A, Gamez L, el Fegoun AB, Hwang K, Pagala M, et al. Adult scoliosis: prevalence, SF-36, and nutritional parameters in an elderly volunteer population. Spine (Phila Pa 1976). 2005;30(9):1082-5. https://doi. org/10.1097/01.brs.0000160842.43482.cd.

4. Jimbo S, Kobayashi T, Aono K, Atsuta Y, Matsuno T. Epidemiology of degenerative lumbar scoliosis: a community-based cohort study. Spine (Phila Pa 1976). 2012;37(20):1763-70. https://doi.org/10.1097/BRS.0b013e31 82575eaa.

5. Graham RB, Sugrue PA, Koski TR. Adult Degenerative Scoliosis. Clin Spine Surg. 2016;29(3):95-107. https://doi.org/10.1097/BSD.0000000000000367.

6. York PJ, Kim HJ. Degenerative scoliosis. Curr Rev Musculoskelet Med. 2017; 10(4):547-58. https://doi.org/10.1007/s12178-017-9445-0.

7. Bokov A, Bulkin A, Aleynik A, Kutlaeva M, Mlyavykh S. Pedicle screws loosening in patients with degenerative diseases of the lumbar spine: potential risk factors and relative contribution. Global Spine J. 2019;9(1):5561. https://doi.org/10.1177/2192568218772302.

8. Galbusera F, Volkheimer D, Reitmaier S, Berger-Roscher N, Kienle A, Wilke HJ Pedicle screw loosening: a clinically relevant complication? Eur Spine J. 2015;24(5):1005-16. https://doi.org/10.1007/s00586-015-3768-6.

9. Sun D, Liu P, Cheng J, Ma Z, Liu J, Qin T. Correlation between intervertebral disc degeneration, paraspinal muscle atrophy, and lumbar facet joints degeneration in patients with lumbar disc herniation. BMC Musculoskelet Disord. 2017;18(1):167. https://doi.org/10.1186/s12891-017-1522-4.

10. Shafaq N, Suzuki A, Matsumura A, Terai $\mathrm{H}$, Toyoda $\mathrm{H}$, Yasuda $\mathrm{H}$, et al. Asymmetric degeneration of paravertebral muscles in patients with 
degenerative lumbar scoliosis. Spine. 2012;37(16):1398-406. https://doi.org/1 0.1097/BRS.0b013e31824c767e.

11. Zotti M, Boas FV, Clifton T, et al. Does pre-operative magnetic resonance imaging of the lumbar multifidus muscle predict clinical outcomes following lumbar spinal decompression for symptomatic spinal stenosis? Eur Spine J. 2017;26(10):2589-97. https://doi.org/10.1007/s00586-017-4986-x.

12. Kim DK, Kim JY, Kim DY, Rhim SC, Yoon SH. Risk factors of proximal junctional kyphosis after multilevel fusion surgery: more than 2 years followup data. J Korean Neurosurg Soc. 2017;60(2):174-80. https://doi.org/10.3340/ jkns.2016.0707.014

13. Hyun SJ, Kim YJ, Rhim SC. Patients with proximal junctional kyphosis after stopping at thoracolumbar junction have lower muscularity, fatty degeneration at the thoracolumbar area. Spine J. 2016;16(9):1095-101. https://doi.org/10.1016/.jspinee.2016.05.008.

14. Kim J, Park S, Lee Y, et al. The effects of spinopelvic parameters and paraspinal muscle degeneration on S1 screw loosening. J Korean Neurosurg S. 2015;58(4):357-62. https://doi.org/10.3340/jkns.2015.58.4.357.

15. Wu JC, Huang WC, Tsai HW, Ko CC, Wu CL, Tu TH, et al. Pedicle screw loosening in dynamic stabilization: incidence, risk, and outcome in 126 patients. Neurosurg Focus. 2011;31(4):E9. https://doi.org/10.3171/2011.7. FOCUS11125.

16. Sanden B, Olerud C, Petren-Mallmin M, Johansson C, Larsson S. The significance of radiolucent zones surrounding pedicle screws. Definition of screw loosening in spinal instrumentation. J Bone Joint Surg Br. 2004;86(3): 457-61.

17. Takayama K, Kita T, Nakamura H, Kanematsu F, Yasunami T, Sakanaka H, et al. New predictive index for lumbar paraspinal muscle degeneration associated with aging. Spine (Phila Pa 1976). 2016;41(2):E84-90. https://doi. org/10.1097/BRS.0000000000001154.

18. Sun Z, Wang Y, Ji S, Wang K, Zhao Y. Computer-aided analysis with Image J for quantitatively assessing psoriatic lesion area. Skin Res Technol. 2015; 21(4):437-43. https://doi.org/10.1111/srt.12211.

19. Okuyama K, Abe E, Suzuki T, Tamura Y, Chiba M, Sato K. Influence of bone mineral density on pedicle screw fixation: a study of pedicle screw fixation augmenting posterior lumbar interbody fusion in elderly patients. Spine $J$. 2001;1(6):402-7. https://doi.org/10.1016/S1529-9430(01)00078-X.

20. Ko CC, Tsai HW, Huang WC, Wu JC, Chen YC, Shih YH, et al. Screw loosening in the Dynesys stabilization system: radiographic evidence and effect on outcomes. Neurosurg Focus. 2010;28(6):E10. https://doi.org/10.31 71/2010.3.FOCUS1052.

21. Katsu M, Ohba T, Ebata S, Oba H, Koyama K, Haro H. Potential role of paraspinal musculature in the maintenance of spinopelvic alignment in patients with adult spinal deformities. Clin Spine Surg. 2020;33(2):E76-80. https://doi.org/10.1097/BSD.0000000000000862.

22. Tang Y, Yang S, Chen C, Luo K, Chen Y, Wang D, et al. Assessment of the association between paraspinal muscle degeneration and quality of life in patients with degenerative lumbar scoliosis. Exp Ther Med. 2020;20(1):50511. https://doi.org/10.3892/etm.2020.8682.

23. Tokuhashi Y, Matsuzaki $\mathrm{H}$, Oda $\mathrm{H}$, Uei $\mathrm{H}$. Clinical course and significance of the clear zone around the pedicle screws in the lumbar degenerative disease. Spine (Phila Pa 1976). 2008;33(8):903-8. https://doi.org/10.1097/BRS. ob013e31816b1eff.

24. Urrutia J, Besa P, Lobos D, Andia M, Arrieta C, Uribe S. Is a single-level measurement of paraspinal muscle fat infiltration and cross-sectional area representative of the entire lumbar spine? Skeletal Radiol. 2018;47(7):939-45. https://doi.org/10.1007/s00256-018-2902-z.

25. Ranson CA, Burnett AF, Kerslake R, Batt ME, O'Sullivan PB. An investigation into the use of MR imaging to determine the functional cross sectional area of lumbar paraspinal muscles. Eur Spine J. 2006;15(6):764-73. https://doi. org/10.1007/s00586-005-0909-3.

26. Kader DF, Wardlaw D, Smith FW. Correlation between the MRI changes in the lumbar multifidus muscles and leg pain. Clin Radiol. 2000;55(2):145-9. https://doi.org/10.1053/crad.1999.0340.

27. Kalimo H, Rantanen J, Viljanen T, Einola S. Lumbar muscles: structure and function. Ann Med. 1989;21(5):353-9. https://doi.org/10.3109/07853 898909149220.

28. O'Sullivan PB, Grahamslaw KM, Kendell M, et al. The effect of different standing and sitting postures on trunk muscle activity in a pain-free population. Spine (Phila Pa 1976). 2002;27(11):1238-44. https://doi.org/10.1 097/00007632-200206010-00019.
29. Creze M, Soubeyrand M, Gagey O. The paraspinal muscle-tendon system: Its paradoxical anatomy. Plos One. 2019;14(4):e0214812. https://doi.org/10.13 71/journal.pone.0214812.

30. Hansen L, de Zee M, Rasmussen J, Andersen TB, Wong C, Simonsen EB. Anatomy and biomechanics of the back muscles in the lumbar spine with reference to biomechanical modeling. Spine (Phila Pa 1976). 2006;31(17): 1888-99. https://doi.org/10.1097/01.brs.0000229232.66090.58.

31. Fortin M, Wilk N, Dobrescu O, Martel P, Santaguida C, Weber MH. Relationship between cervical muscle morphology evaluated by MRI, cervical muscle strength and functional outcomes in patients with degenerative cervical myelopathy. Musculoskelet Sci Pract. 2018;38:1-7. https://doi.org/10.1016/j.msksp.2018.07.003.

32. Yu BS, Zhuang XM, Zheng ZM, Zhang JF, Li ZM, Lu WW. Biomechanical comparison of 4 fixation techniques of sacral pedicle screw in osteoporotic condition. J Spinal Disord Tech. 2010;23(6):404-9. https://doi.org/10.1097/ BSD.0b013e3181b63f4d.

33. Yang X, Kong Q, Song Y, Liu H, Zeng J, Liu L. Clinical application of pedicle screw fixation under guidance of computer assisted navigation in patients with osteoporosis. Zhongguo Xiu Fu Chong Jian Wai Ke Za Zhi. 2012;26(2): 196-200.

\section{Publisher's Note}

Springer Nature remains neutral with regard to jurisdictional claims in published maps and institutional affiliations.
Ready to submit your research? Choose BMC and benefit from:

- fast, convenient online submission

- thorough peer review by experienced researchers in your field

- rapid publication on acceptance

- support for research data, including large and complex data types

- gold Open Access which fosters wider collaboration and increased citations

- maximum visibility for your research: over $100 \mathrm{M}$ website views per year

At BMC, research is always in progress.

Learn more biomedcentral.com/submissions 